\title{
Marine spatial planning for resource conservation, fisheries management and for ensuring fishermen security - global perspectives and Indian initiatives
}

\author{
A. P. Dineshbabu ${ }^{1 \%}$, Sujitha Thomas ${ }^{1}$, Prathibha Rohit ${ }^{1}$ and G. Maheswarudu ${ }^{2}$ \\ ${ }^{1}$ Mangalore Research Centre of Central Marine Fisheries Research Institute, Hoige Bazar, Mangaluru 575 001, India \\ ${ }^{2}$ Central Marine Fisheries Research Institute, Kochi 682 018, India
}

Internationally, marine spatial planning (MSP) is an integral part of the decision-making protocol for setting up activities in the marine zone, be it the establishment of industries, exploration and mining for oil and minerals, deciding of surface transport, ensuring national security, exploitation of living and non-living resources, or conservation and management of resources and ecosystems. Satellite-based technologies like remote sensing and geographic information system are two powerful tools that provide a common platform to present information on different activities from the marine zone. This would enable the planners and policymakers to interpret the interaction between various factors and derive judicious decisions on the allocation of space and resources to different segments or activities in marine zone. This article reviews how MSP is being used as a decisionsupport tool in various countries for the peaceful coexistence of different stakeholders in the marine zone. It also discusses initiatives in India along with a reminder on the responsibility of the country as a signatory of international organizations to give importance on developing MSP for the conservation of resources as well as marine ecosystems.

Keywords: Fishermen security, mariculture, marine spatial planning, resource conservation, satellite-based technology.

MARINE spatial planning (MSP) is a conceptual decisionmaking process in the marine zone to decide what to do, where to do and how to do; it also implies what not to do. Viewing from the fisheries perspective, MSP can be a decision process for ensuring safety of life and implements of fishermen and the coastal population, for fisheries management, resource conservation, sustainable exploitation and mariculture production. Though the marine resources are considered a focal point for environmental clearance of activities, the human factor which includes fishermen and fishing activities, is not given

*For correspondence. (e-mail: dineshbabuap@yahoo.co.in) adequate importance in marine systems. Importance of MSP for ensuring healthy coexistence of multiple users and also for marine resource conservation is well recognized by most of the countries ${ }^{1}$. MSP and ocean zoning have been developed for managing the multiple uses of marine space. In the context of multi-use planning of ocean space, MSP is now a tool to conserve nature, especially biologically and ecologically sensitive areas ${ }^{2}$. MSP is routinely used as a decision support tool in various countries for peaceful coexistence of different stakeholders in the marine zone. It also serves in conserving critical ecosystems in terms of fishery as well as biodiversity. Importance and need for developing MSP for marine resource conservation and identifying marine protected areas were discussed in the first Earth Summit in 1992, wherein all member countries agreed to establish MSPbased national network of Marine Protected Areas (MPAs) by 2012 (ref. 3). The Conference of the Parties to the Convention on Biological Diversity, during their 13th meeting in Mexico in 2016, also emphasized the importance and need for developing MSP for fishery conservation $^{4}$.

MSP is becoming an essential step to achieve ecosystem-based management, catch, bycatch issues, mariculture development, etc. Focus of MSP in different countries varies from marine biodiversity conservation (Australia, Canada), conflict management and inter-sector resource management (USA and Taiwan), scaling up of coastal and marine zone-based technologies, including fishing and mariculture (China) and resource sharing and resource conservation with international cooperation (European countries) ${ }^{1}$.

MSP for marine resource conservation was done in Australia in the 1980s for zoning of the Great Barrier Reef Marine Park ${ }^{5}$. MSP was taken up under national and regional level legislative bodies. The Australian Ocean Policy 1998 provided provisions for MSP to facilitate the integration and coordination of all the agencies and departments having a stake in the marine zone (Commonwealth of Australia, 1998); it was called as regional marine plans (RMPs). 
In European countries, where marine space and resource sharing is a serious concern, MSP was given high priority. In 2005, RMPs were changed into marine bioregional plans (MBPs), and were given statutory recognition through Environment Protection and Biodiversity Conservation (EPBC Act, 1999). In Germany, the Netherlands, Spain and Sweden, the concept was included in the policy in 2004, 2005, 2010 and 2011 respectively ${ }^{1}$. These processes were called marine spatial planning. In Poland (2003) and Portugal (2010), MSP was referred to as maritime spatial planning. MSP was adopted by the United Kingdom (2010) as 'marine planning' (MP) and Norway (2006) in the form of integrated management ${ }^{1}$. The European Commission in its efforts to implement MSP in the years to come, provided an European MSP platform as a communication gateway to offer support to all EU member states. With the adoption of the EU Directive on Maritime Spatial Planning, all coastal EU member states are required to prepare a cross-sector maritime spatial plan by 2021. This will be a model platform funded by the EU Directorate General for Maritime Affairs and Fisheries (DG MARE), and will allow officials, planners and other stakeholders interested in MSP to build on what is already available to assist in capacity building and foster the development of new practices ${ }^{1}$.

The USA passed an executive order in 2010 highlighting the need to coordinate ocean uses via regional ocean plans to be implemented by the regional planning bodies (RPBs), as a solution to reduce ongoing conflicts due to intense inter-sector use of marine resources. This is referred to as coastal and marine spatial planning (CMSP). The Canada Network of Marine Protected Areas approved in principle by the Canadian Council of Aquaculture ministers in 2011, was the formal recognition for $\mathrm{MSP}^{1}$.

In Asian countries, MSP was referred to as marine functional zoning (MFZ) and has been practised since 1980. In China and Taiwan, MSP (MFZ) is effective since 2012 (ref. 6).

\section{Indian scenario}

Marine spatial planning is still in its infancy in India and marine zoning is done in certain areas. The Comprehensive Marine Fishing Policy ${ }^{7}$ (released by the Ministry of Agriculture, Department of Animal Husbandry and Dairying, Government of India) refers to marine zoning for mechanized and traditional sector (Section 3.4 of Marine Fishing Policy, 2004). Section 3.4 states that 'Within the territorial waters, the demarcation of the area for traditional, motorized and small-mechanized fishing vessels is the purview of the coastal state/union territory'. Such zoning of the marine areas is a part of the MSP (Box 1). The regulative powers within the Indian coastal zone are being executed by eight Central Government ministries and a similar number of State Government agencies ${ }^{8}$, with decision-making becoming difficult in Indian coastal zone development. Even though MSP terminology is not used, the concept of MSP has been the basic requirement of clearing marine projects in India also, and has been a part of environmental impact assessment (EIA) studies for a long time. Information on fishing, the most dynamic human activity in the maritime zone is missing in marine development plan approvals in India, which often causes unanticipated conflicts in the sea, competing for space and resources. According to the fishery census 2010 (ref. 9 ), about a million $(990,083)$ fishermen are at sea operating about 2 lakh fishing vessels $(194,490)$.

\section{Inputs for MSP from the fisheries sector}

Marine fishing activities are highly dynamic with seasonal changes in areas of operation and depth of operation ${ }^{7}$. Real-time documentation of such information from India was thus far considered impossible and the meagre data available were found to be poor or insufficient due to lack of spatial dimensions to be accepted in policy decisions. In the present fishing scenario, the installation of satellite-based equipments in trawlers and other mechanized vessels, enables them to collect data on distribution and abundance of marine living resources in spatial format and the expertise in the use of GIS tools helps to process these data for decision support in fisheries management ${ }^{11}$. This could be one of the inputs for MSP, which would enable policy makers to suggest suitable decisions for marine zone management (Box 2).

The Central Marine Fisheries Research Institute (CMFRI), Kochi has initiated collecting and documenting these activities in the marine zone in a spatial platform by preparing an inventory of fishing activities and fishery information (Box 3). The inventory contains fisheriesrelated activities in the coastal and marine zones, methods of fishing and zonation in the fishing area with sector demarcation. Extension of the fishing area allied information regarding socio-economic activities also forms a part of the spatio-temporal directory, which would help convey fishery-related information for MSP

Box 1. Territorial waters.

Territorial waters or a territorial sea, as defined by the 2013 United Nations Convention on the Law of the Sea, is a belt of coastal waters extending at most 12 nautical miles $(22.2 \mathrm{~km}$; $13.8 \mathrm{mi})$ from the baseline (usually the mean low-water mark) of a coastal state. The territorial sea is regarded as the sovereign territory of the state, although foreign ships (civilian) are allowed innocent passage through it, or transit passage for straits; this sovereignty also extends to the airspace over and seabed below ${ }^{34}$. 
in India ${ }^{11}$. The document, which is the first of its kind, depicts GIS location of 1278 existing fishing centres (Figure 1), fishing activities including seasonality of fishing, and spatial extent of fishing activities in each season. The data were used to draw GIS-based gear-wise fishery operation maps (viz. gillnet, trawl, dol net, shore seine, ring seine, purse seine, Chinese dipnet, and hook and line) in the country. The database is available on request from the Director, CMFRI, Kochi, and organizations like the Indian Navy and the Indian Coast Guard are some of the premier benefactors of this database.

\section{MSP for ensuring safety of fishermen and implements}

Ensuring safety of life and appliances of fisherfolk can be achieved through MSP. This requires methodical recording of the activities of fishermen and extension of fishing activities in space and time. In light of intense multisector activities in the sea, like shipping, national security and defence activities, oil exploration, mining and tourism, most Government bodies face extreme difficulty

\section{Box 2. Trawling}

Trawling is a mechanised fishing method, which is considered as the most efficient technological intervention for fishing and has contributed substantially to the increased global marine fish production. In India by the year 2000 , more than $50 \%$ of Indian marine fish catch was contributed by trawlers ${ }^{17}$. But in recent years due to its irrational operations, an immediate need for regulation of trawl fishery was considered as a measure for sustainable production, as its extensive combing of sea bottom is causing widespread damage to marine biota ${ }^{35}$.

\section{Box 3. Methodology used for mapping.}

Spatio-temporal data for the mapping of fishing cruises, fishing pressure and fishery distribution, which are illustrated in the document were collected from identified commercial trawlers operating from the Indian coast. The cruise paths traditionally followed by trawl fishermen were recorded for the mapping. To understand the fishing pressure in different fishing grounds, individual cruise lines in particular fishing grounds were classified into low and high fishing intensity based on the number of visits by trawlers in the $0.25 \mathrm{~km}^{2}$ grid in the fishing ground polygon. For spatio-temporal distribution mapping and smooth handling of data, two software were used-ArcGIS and Visual Basic (VB) 6. Detailed methodology for mapping following standard methodologies customized for Indian fishing scenario was also published $^{10}$. to derive a balance between conservation concerns and economic development needs ${ }^{12}$. MSP in GIS platform can be used to address safety issues of fishers and local communities by bringing their operations in the coastal and marine zone in a transferable format. Maritime ship collisions involving fishing boats have often been reported in many countries ${ }^{13}$, and MSP is becoming an increasingly important tool for ensuring safety in the navigation route. The Ocean Council has instructed maritime professionals to collect information on other users of waterways space, from both sea and shore, and to take part in international, regional, national and local MSP debates. This was suggested to ensure understanding of the needs of other marine users and resources. In the Pacific ${ }^{14}$ and Oceania ${ }^{15}$, such experiments proved successful with fishermen voluntarily supplying data for ensuring their security.

There are different kinds of monitoring mechanisms available around the world which along with vessel movement monitoring ensure the safety of fishermen at sea. Vessel monitoring systems (VMS), automatic identification system (AIS), long range identification and tracking (LRIT), COSPAS-SARSAT system and global maritime distress and safety system (GMDSS) are some systems suggested by USA for ensuring the safety of vessels in the sea. VMS is extensively used by most of the countries to track vessel locations ${ }^{16}$.

In India, $37 \%$ of the fishing crafts $(143,890)$ are mechanized or motorized, and capable of regular fishing operation beyond territorial waters ${ }^{17}$. Lack of documents/records and lack of agencies for proper exchange of information which can be understood by all sectors are being projected as the major shortcomings for efficient

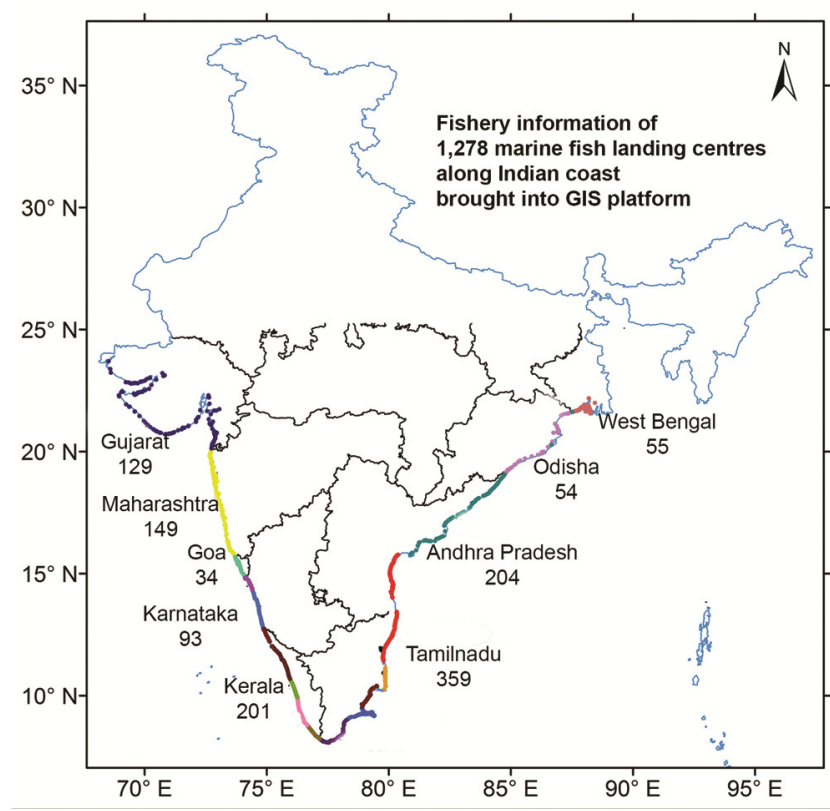

Figure 1. Map representing the number of marine fish landing centres brought under GPS platform for sharing fishing and fishery-related information for marine spatial planning (MSP). 


\section{REVIEW ARTICLES}

MSP in coastal waters. Collision of large ships with fishing boats is becoming frequent in Indian seas. Information on ship movement regularly conveyed to different users of the marine zone would effectively reduce such accidents and loss of life and property of fishermen at sea. For this, exhaustive database creation on fishing vessel movements, with involvement of fishermen is essential. CMFRI has taken up a project 'GIS based mapping of shellfish and finfish around Indian coast' during 2012-2017, with data collection from 10 maritime centres extending from Gujarat to West Bengal ${ }^{11}$. Along with fishery resource mapping, fishing activity mapping was also carried out under the project (Figure 2). The methodology developed for the mapping of fishing activities and fishery resources was also published by CMFRI for encouraging such efforts in future ${ }^{10}$. The maps developed could serve as a tool in other sectors in the maritime zone in planning their activities and be vigilant while carrying out activities along probable fishing tracks. Shipping industry and agencies associated with national security and defence services will also be benefited by these maps.

Lack of vessel-tracking system for fishing vessels is one of the biggest constraints in MSP in Indian waters. The Indian Space Research Organisation has developed IRNSS, an independent regional navigation satellite system which is designed to provide accurate position information service to users in India as well as the region extending up to $1500 \mathrm{~km}$ from its boundary, which is its primary service area. IRNSS has the facility for vesseltracking and this will be useful in developing indigenous VMS for India.

\section{MSP for marine biodiversity conservation, fishing pressure regulation, identifying marine protected areas and fishery refugia}

Resource mapping in GIS platform can reveal the availability and abundance of species in space and time to suggest the possible fishery zones for increasing fishery. The Food and Agriculture Organization (FAO), Rome has published reports on resource mapping and the progress made in different countries ${ }^{18,19}$. The ecosystem approach is being applied to fisheries management and allocation, in which the fishing area and intensity are being decided according to the resource distribution ${ }^{2,20}$. In the marine regime, there are different ecosystems with segregation of fish according to their habits of feeding, breeding, etc. In the pelagic realm, aggregating drives vary unpredictably, whereas in the demersal realm the aggregating areas are more or less predetermined as long as the environmental conditions are favourable.

There is severe stress on the marine environment and resources due to increase in population and unhealthy competition $^{21}$, and fishing is considered to be the most important anthropogenic activity which imparts heavy stress on marine ecosystems with overfishing bycatch, juvenile and spawner exploitation ${ }^{22,23}$. Trawl footprint is a GIS mapping procedure that helps to identify fishing pressure, vulnerable ecosystems in terms of high fishing pressure, biodiversity loss through bycatch and bottom destruction, and heavy exploitation of juvenile and spawners $^{24}$. Based on trawl footprint studies, spatial and temporal restrictions on fishing in these critical ecosystems can be suggested as remedial measures for the revival of ecosystems and resources ${ }^{25}$.

Resource mapping for fishery exploitation was carried out in India during the nineties with data collected during exploratory surveys ${ }^{26-28}$. CMFRI has carried out GISbased marine resource mapping of finfish and shellfish along the Indian coast ${ }^{10,11,29}$. These maps provide spatial dimension to the fish catch database from Indian waters, which would serve as guidelines for deriving fishery management plans in a spatial format.

Figure 3 shows trawl footprint analysis of trawl fishing pressure along the southwest coast of India. MSP will provide answers on where not to fish, and also where and when the fishing should be regulated to conserve biodiversity. With the GIS-based initiative, CMFRI collected and documented information on nursery and spawning grounds of more than 50 commercially important species from the southwest coast of India. This information is an illustrative testimony to suggest the areas of 'fisheries refugia' or 'marine protected areas' in Indian waters. Some of the findings have already found place in policy measures (Figure 4) suggested in marine fisheries policy of the maritime states in India ${ }^{30}$.

\section{MSP to support efficient fishery administration to resolve inter-state and inter-sector conflicts}

In India, from a legislative point of view, 'fisheries' is a 'subject' under state list according to Article 21 of the

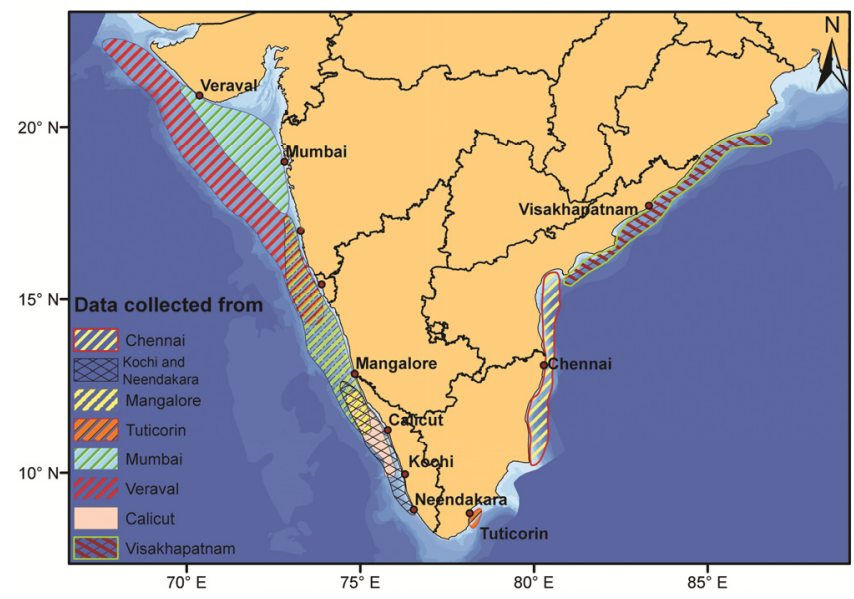

Figure 2. Mapping of extension of trawl fishing cruise routes from different states along the Indian coast to aid in MSP for ensuring fishermen safety ${ }^{14}$. 
Indian Constitution, and management and control of coastal fisheries is vested with the maritime States and Union Territories. The Comprehensive Marine Fishing Policy $^{7}$ of the Ministry of Agriculture, Government of India, released in 2004 reviewed the present status of fishery regulation in coastal waters. It recognizes that, though the Marine Fisheries Regulation Acts (MFRAs) of coastal States and Union Territories have adequate provisions for management of resources and fishing operations, they are often found falling short of effective implementation. It also raised concern that exploitation of living resources within $50 \mathrm{~m}$ depth zone is showing symptoms of depletion and in certain belts, in the inshore waters it tends to cross optimum sustainable levels. One of the most promising suggestions in the Policy is to introduce marine spatial planning and ecosystem-based fisheries management ${ }^{7}$. With spatial analysis of catch and effort data, it is possible to point out some of the inherent difficulties in implementation of fishery-related policies, and to review the present allocation of judicial powers along Indian coastal waters to solve inter-sector and intra-sector conflicts ${ }^{31}$. Territorial waters which were considered as a State fishery administrative boundary, lack

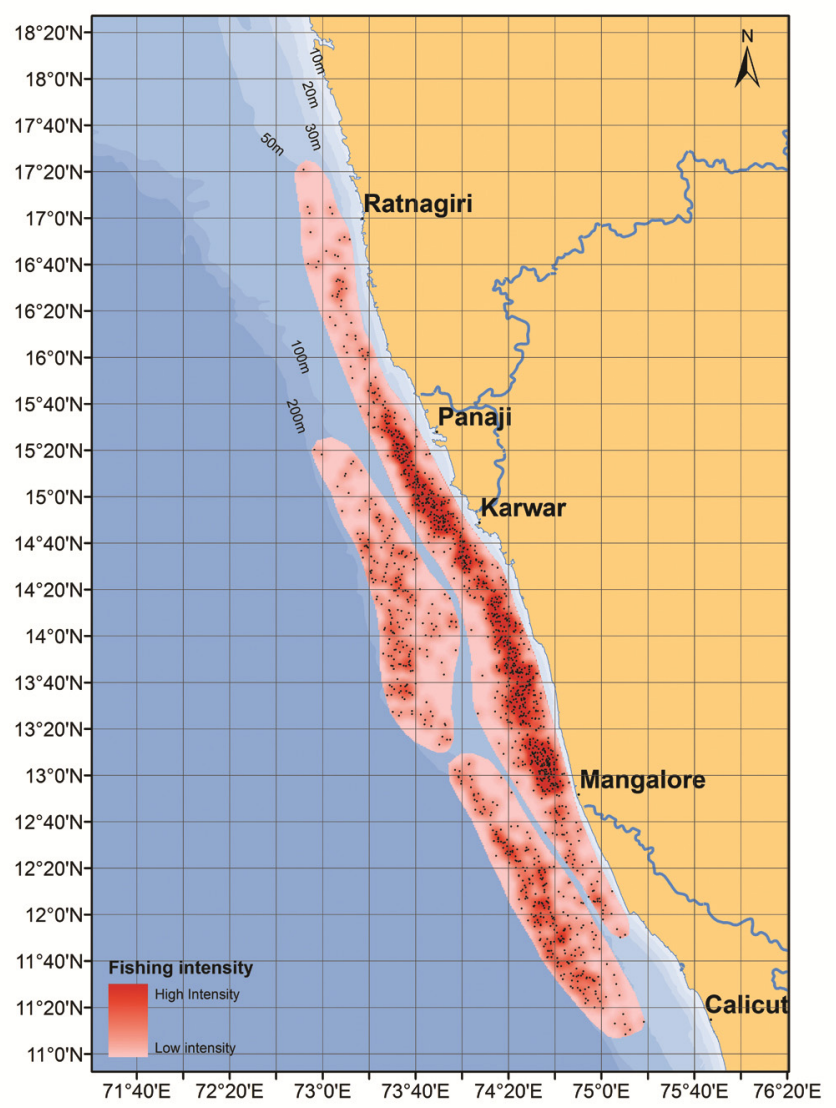

Figure 3. Trawl footprint studies used to identify vulnerable marine ecosystems due to excessive fishing pressure ${ }^{31}$. (High and low intensity were mapped using Intensity tool in GIS software based on the number of visits by the sampling trawler in the fishing grid with resolution of $0.25 \mathrm{~km}^{2}$.) legislative significance since fishing operations from most of the States extend beyond their territorial waters. Regional marine spatial planning with regional cooperation of different States coordinated by a body governed by the Central Government is suggested as a probable option for effective implementation of policies in the marine sector, and also to reduce inter-state, and inter-sector conflicts. Spatial dimension to the data collected will help in regular updating of information for strengthening fisheries administration ${ }^{31}$.

\section{Identification of coastal aquaculture and mariculture sites with MSP}

GIS-based analytical tools are needed to evaluate and incorporate the economic and social considerations that will be critical to identify potential sites and for achieving successful marine spatial planning. FAO has listed out the utilities of GIS-based MSP for mariculture development in detail ${ }^{32}$. The advances in GIS-based decision support tools in relation to their capability for aquaculture site selection and their integration into multiple-use MSP review is also available internationally ${ }^{33}$. Reconciling

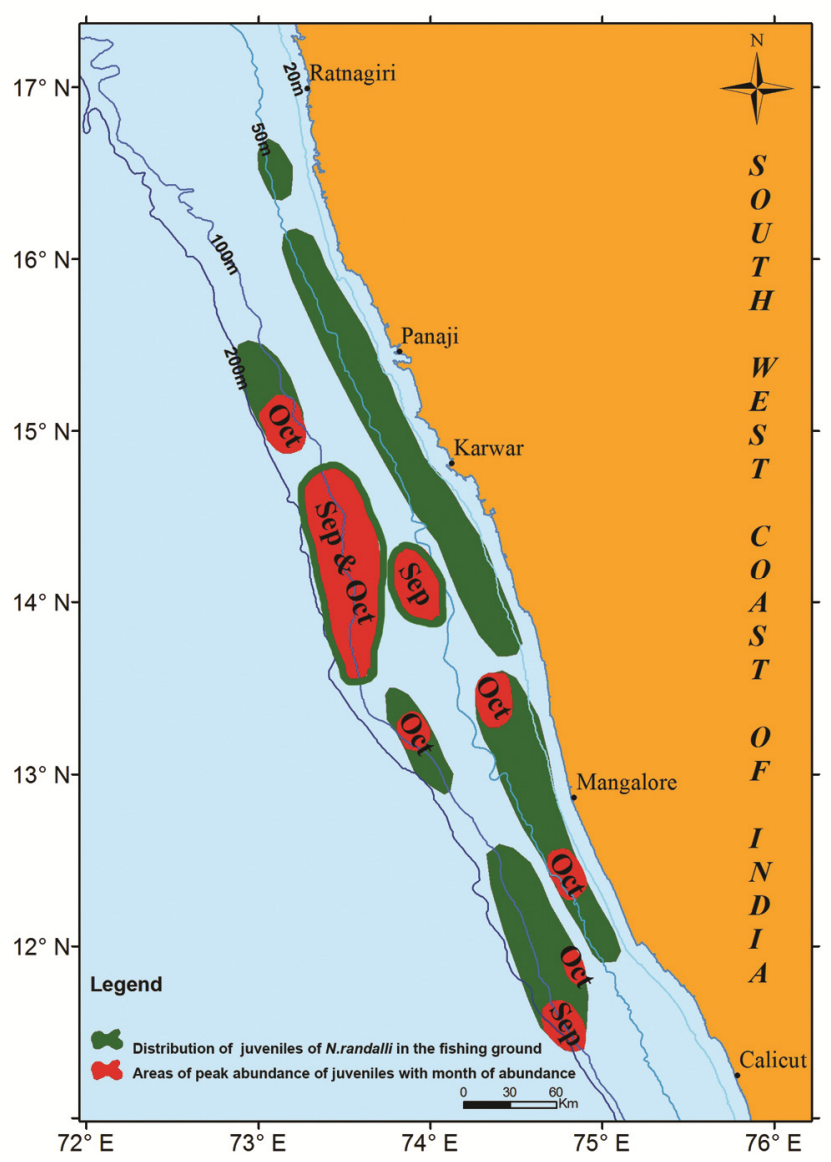

Figure 4. Critical ecosystem identified with respect to juvenile fishery of threadfin bream, one of the major species along the southwest coast of India ${ }^{30}$. 


\section{REVIEW ARTICLES}

ocean uses through MSP, potential benefits of MSP to aquaculture, decision support systems for MSP and aquaculture site selection, the importance of spatial data in the planning process, combining offshore wind energy and aquaculture are the topics are also discussed in the review in, which could serve as a guideline for anyone venturing into mariculture ${ }^{33}$. Site selection for the identified culture practice is of utmost importance for success, in which information on environmental/hydrographical features plays a major role. GIS-based projection technologies are found to be useful in analysing each site and to simulate the scenarios during and after the culture; and in most of the countries now these technologies are integrated with EIA studies ${ }^{33}$.

Introduction of new technology in a well-established system may create conflicts among human uses (useruser conflicts) and also between human uses and the marine environment (user-environment conflicts). MSP can provide a desktop solution in planning maritime development activities and allocation of areas for sustaining production of marine products as well as other economic activities. This enables us to prioritize the distribution of space and water, and also helps in ecofriendly farming practices without harming the marine ecosystem. MSP can bring out all the activities along the coastal area studied in a format that can be easily understood by all. MSP through ocean space mapping has a provision to monitor the ongoing mariculture activities in coastal waters and open sea in a spatial platform for ensuring human and eco-friendly mariculture development.

\section{Conclusion}

Review of the international status shows that MSP is taken as a basic instrument for sustainable development in the marine sector by almost all the countries. In the Indian scenario, MSP does exist as a part of EIA studies to develop new ventures in the sea, but that does not cover fishing operations or fishery resource information. The complexity and dynamic nature of fishing sector need to be disseminated to all concerned sectors in the marine zone, so that proper precautions can be taken up by them for ensuring safety of life and property of fishermen; fishermen should take up the responsibility to update the database from time to time. From environment point of view, mapping of fishing pressure and distribution of fishery resources are extremely important decision support tools for conservation and management of marine biodiversity and marine fisheries resources in space and time. CMFRI has already initiated resource mapping to support MSP in Indian waters with documentation methodologies for the marine resource mapping and fishing operation mapping. The support for fisheries sector in MSP in Indian waters may be improved, thus ensuring sustainable development in the marine sector. MSP requires multi-institutional framework for overall peaceful and prosperous coexistence in the marine zone, with stress on human welfare, resource conservation and overall development of the country.

1. Jay, S. et al., Coastal and marine spatial planning. In Ocean Yearbook (eds Chircop, S., Smout, C. and McConnell, M.), Brill, Leiden, The Netherlands, 2013, pp. 171-212.

2. Douvre, F., The importance of marine spatial planning in advancing ecosystem based seas use management. Mar. Policy, 2008, 32, $762-771$.

3. Agenda 21 adopted at UNCED, Rio de Janeiro, Brazil, 3-14 June 1992; http://www.un.org/ESA/sustdev/documents/agenda21/english/ agens21.pdf

4. Report of the Conference of the Parties to the Convention on Biological Diversity on its Thirteenth Meeting, Cancun, Mexico, 4-17 December 2016; https://www.cbd.int/doc/c/ccf8/86e1/258e841f696315c3212d9259/cop-13-25-en.pdf

5. Day, J., Zoning: lesson from Great Barrier Reef Marine Park. Ocean Coast. Manage., 2002, 45, 139-156.

6. Liu, Y., Feng, A. and Wu, S., Assessment methods and case study of the implementation of marine functional zoning. Ocean Dev. Manage., 2009, 26, 12-17.

7. Department of Animal Husbandry, Dairying and Fisheries, Comprehensive Marine Fishing Policy. Planning Commission, Government of India, 2004.

8. Radhakrishnan, E. V. and Dineshbabu, A. P., Regulatory framework for mariculture development and management. In Handbook on Opensea Cage Culture, Central Marine Fisheries Research Institute, Karwar, 2012, pp. 15-26.

9. Marine Census 2010, Ministry of Agriculture, Krishi Bhavan, New Delhi and CMFRI, Kochi, Part I is India, CMFRI, Kochi, 2012.

10. Dineshbabu, A. P., Thomas, S. and Dinesh, A. C., Handbook on Application of GIS as a Decision Support Tool in Marine Fisheries, CMFRI Spec Publ. No. 121, ICAR-Central Marine Fisheries Research Institute, Kochi, 2016, p. 104.

11. CMFRI Annual Report 2016-2017, Technical Report. Central Marine Fisheries Research Institute, Kochi, 2017, pp. 34-35.

12. Jentoft, S. and Knol, M., Marine spatial planning: risk or opportunity for fisheries in the North Sea? Marit. Stud., 2014, 12(13), $1-116$.

13. Kao, S. L. and Chang, K. Y., Study on fuzzy GIS for navigation safety of fishing boats. J. Mar. Eng. Technol., 2017, 16(2), 8384.

14. Calamia, M. A. A., Methodology for incorporating traditional ecological knowledge with geographic information systems for marine resource management in the Pacific. In SPC Traditional Marine Resource Management and Knowledge Information Bulletin \#10, 1999, pp. 2-12.

15. Aswani, S. and Lauer, M., Incorporating fishermen's local knowledge and behavior into geographical information systems (GIS) for designing marine protected areas in Oceania. Human Org., 2006, 65(1), 81-102.

16. Chang, S.-K., Liu, K.-Y. and Song, Y.-H., Distant water fisheries development and vessel monitoring system implementation in Taiwan - history and driving forces. Mar. Policy, 2010, 34, 541548.

17. Srinath, M., An appraisal of the exploited marine fishery resources of India. In Status of Exploited Marine Fishery Resources of India (eds Mohan Joseph, M. and Jayaprakash, A. A.), CMFRI, Cochin, 2003, pp. 1-17.

18. Butler, M. J. A., LeBlanc, C., Belbin, J. A. and MacNeill, J. L., Marine resource mapping: an introductory manual. FAO Fish. 
Tech. Paper No. 274, Food and Agriculture Organization (FAO), Rome, 1986, p. 256.

19. Meaden, G. J. and Do Chi, T., Geographical information systems: applications to machine fisheries. FAO Fisheries Technical Paper, No. 356. Rome, FAO, 1996, p. 335.

20. Rubec, J. P., Introduction to a Special Section: Spatial Analysis, Mapping, and Management of Marine Fisheries. Mar. Coast. Fish., 2016, 8(1), 132-134.

21. Halpern, B. S., Walbridge, S. and Selkoe, K. A., A global map of human impact on marine ecosystems. Science, 2008, 319, 948952.

22. Dayton, P. K., Thrush, S. F., Agardy, M. T. and Hofman, R. J., Environmental effects of marine fishing. Mar. Freshwater Ecosyst., 1995, 5, 205-232.

23. Jackson, J. B. C. et al., Historical overfishing and the recent collapse of coastal ecosystems. Science, 2001, 293, 629.

24. Black, J., Wood, R., Berthelsen, T. and Tilney, R., Monitoring New Zealand's trawl footprint for deepwater fisheries: 1989-1990 to 2009-2010. In New Zealand Aquatic Environment and Biodiversity Report, Ministry of Primary Industries, New Zealand, 2001, report no. 110 , p. 57.

25. Daniel, D. C., Boustany, A. M. and Halpin, P. N., Spatio-temporal management of fisheries to reduce by-catch and increase fishing selectivity. Fish Fish., 2011, 12, 110-119.

26. Sivakami, S., Observations on the demersal fishery resources of the coastal and deep sea areas of the Exclusive Economic Zone of India. In Proceedings of the First Workshop on Scientific Results of FORV Sagar Sampada, 1990, pp. 315-330.

27. Suseelan, C., Nandakumar, G. and Rajan, K. N., Results of bottom trawling by FORV Sagar Sampada with special reference to catch and abundance of edible crustaceans. In Proceedings of the First Workshop on Scientific Results of FORV Sagar Sampada, 1990, pp. 337-346.

28. Suseelan, C. et al., Further observations on the spatial distribution and population characteristics of 'karikkadi' prawn (Parape- naeopsis stylifera) along the Kerala coast during monsoon season. Indian J. Fish., 1998, 45(3), 285-292.

29. CMFRI Annual Report 2014-2015, CMFRI, Kochi, 2015, pp. 2529.

30. Rohit, P. et al., Management plans for the Marine Fisheries of Karnataka. Marine Fisheries Policy Series-5. CMFRI, Kochi, 2016, pp. 1-110.

31. Dineshbabu, A. P., Thomas, S. and Shailaja, S., Efficacy of spatial study on catch and effort from fishing vessels for strengthening fisheries management. J. Mar. Biol. Assoc. India, 2017, 59(1), 3135.

32. Kapetsky, J. M. and Aguilar-Manjarrez, J., Geographic information systems, remote sensing and mapping for the development and management of marine aquaculture. FAO Fisheries Technical Paper No. 458, Rome, FAO, 2007, p. 125.

33. Vanessa, S., Gimpel, A., Gopnik, M. and Gee, K., Aquaculture site-selection and marine spatial planning: the roles of GIS-based tools and models. In Aquaculture Perspective of Multi-Use Sites in the Open Ocean (eds Buck, B. H. and Langan, R.), Springer Open, 2017, pp. 131-148.

34. UN General Assembly, Convention on the Law of the Sea, Dec. 10, 1982, 1833 United Nations Treaty Series 397. Enacted as: entered into force as the United Nations Convention on the Law of the Sea on 1 November 1994.

35. Devaraj, M. and Vivekanandan, E., Marine capture fisheries of India: Challenges and opportunities. Curr. Sci., 1999, 76(3), 314332 .

ACKNOWLEDGEMENT. We thank Dr A. Gopalakrishnan, Director, Central Marine Fisheries Research Institute, Kochi for encouragement and support.

Received 13 June 2018; revised accepted 15 November 2018

doi: $10.18520 /$ cs/v116/i4/561-567 